\title{
Article \\ Environmental Risk Assessment of Oxaliplatin Exposure on Early Life Stages of Zebrafish (Danio rerio)
}

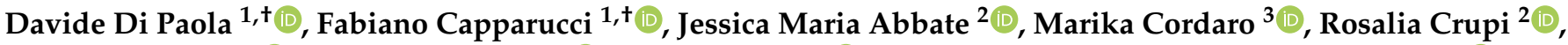

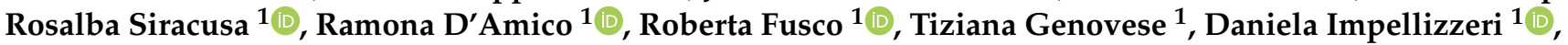

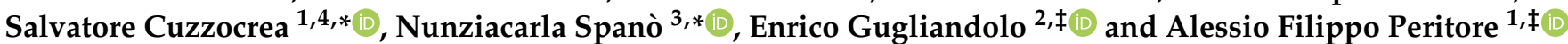

\section{check for}

updates

Citation: Di Paola, D.; Capparucci, F.; Abbate, J.M.; Cordaro, M.; Crupi, R.; Siracusa, R.; D'Amico, R.; Fusco, R.; Genovese, T.; Impellizzeri, D.; et al. Environmental Risk Assessment of Oxaliplatin Exposure on Early Life Stages of Zebrafish (Danio rerio). Toxics 2022, 10, 81. https://doi.org/ $10.3390 /$ toxics 10020081

Academic Editors: Stefanos Dailianis and Konstantinos Gkrintzalis

Received: 17 January 2022

Accepted: 2 February 2022

Published: 9 February 2022

Publisher's Note: MDPI stays neutral with regard to jurisdictional claims in published maps and institutional affiliations.

Copyright: (C) 2022 by the authors. Licensee MDPI, Basel, Switzerland. This article is an open access article distributed under the terms and conditions of the Creative Commons Attribution (CC BY) license (https:// creativecommons.org/licenses/by/ $4.0 /)$.
1 Department of Chemical, Biological, Pharmaceutical, and Environmental Science, University of Messina, 98166 Messina, Italy; davide.dipaola@unime.it (D.D.P.); fabiano.capparucci@unime.it (F.C.); rsiracusa@unime.it (R.S.); rdamico@unime.it (R.D.); rfusco@unime.it (R.F.); tgenovese@unime.it (T.G.); dimpellizzeri@unime.it (D.I.); aperitore@unime.it (A.F.P.)

2 Department of Veterinary Science, University of Messina, 98166 Messina, Italy; jessica.abbate@unime.it (J.M.A.); rcrupi@unime.it (R.C.); egugliandolo@unime.it (E.G.)

3 Department of Biomedical and Dental Sciences and Morphofunctional Imaging, University of Messina, 98125 Messina, Italy; cordarom@unime.it

4 Department of Pharmacological and Physiological Science, Saint Louis University School of Medicine, Saint Louis, MO 63104, USA

* Correspondence: salvator@unime.it (S.C.); nunziacarla.spano@unime.it (N.S.); Tel.: +39-90-6765208 (S.C.)

+ These authors contributed equally to this work.

$\ddagger$ These authors shared senior authorship.

\begin{abstract}
Pharmaceuticals are actually identified as a threat to the ecosystem. Nowadays, the growing consumption of antineoplastic agents has been related to their continuous input in natural environments. These substances can interfere with physiological and biochemical processes of aquatic species over their entire life cycle. Oxaliplatin (OXA) is a widely used chemotherapeutic agent to treat colon or rectal cancer. This study was aimed to evaluate the developmental toxicity of the OXA exposure. To this end, zebrafish embryos were incubated with $0.001,0.1,0.5 \mathrm{mg} / \mathrm{L} \mathrm{OXA}$. At different timepoints mortality rate, hatching rate, developmental abnormalities, histological analysis, oxidative stress and mRNA expression of gene related to oxidative stress were evaluated. Our results showed that OXA exposure can induce increased mortality and developmental abnormalities reducing the hatching rate. Histological analysis demonstrated that OXA induced liver, intestine, muscle and heart injury. Superoxide dismutase and catalase activities were significantly increased after OXA exposure demonstrating its oxidative effects. The mRNA expression levels of apoptosis-related genes (caspase-3, bax and bcl-2) were significantly upregulated by OXA exposure. In conclusion, we highlighted that OXA exposure led to a dose-related developmental toxicity, oxidative stress and apoptosis.
\end{abstract}

Keywords: oxaliplatin; developmental toxicity; ROS; cell death

\section{Introduction}

Global Cancer Statistics 2020 (GLOBOCAN) estimates that 19.3 million new cancer cases and about 10.0 million cancer deaths occurred globally in 2020. Data of the World Health Organization (WHO) place the use of anticancer drugs among the eight categories of medicines most employed on the planet. Platinum-based antineoplastic agents are widely used in chemotherapy. They crosslink DNA strands or form DNA-protein crosslinks in cancer cells $[1,2]$ and include cisplatin (CDDP), carboplatin (CARP) and oxaliplatin (OXA). Several studies have shown that exposure to platinum or its derivatives, such as cisplatin, may result in genotoxic and teratogenic effects during the early stages of zebrafish embryonic development $[3,4]$. OXA is a chemotherapeutic agent used to treat colon or rectal cancer that has spread (metastasized) [5]. It is frequently used in conjunction with 
other anticancer medications (fluorouracil and leucovorin). The anticancer mode of action of platinum-complex drugs is owing to the development of platinum adjuncts between adjacent DNA bases, and it is classed as "alkylating agent". OXA selectively inhibits the synthesis of deoxyribonucleic acid (DNA), the guanine and cytosine content correlates with the degree of OXA-induced cross-linking. At high concentrations of the drug, cellular RNA and protein synthesis are also suppressed [5]. OXA varies from cisplatin in that diaminocyclohexane replaces the amine groups in cisplatin (dach). After administration, anticancer drugs are excreted in urine and feces; OXA is mostly excreted through the kidneys: after $48 \mathrm{~h}$, around half of the administered dose is detected in the urine. The liver excretes between 2 and 5\% of the dosage. In patients with poor renal function, oxaliplatin clearance has been found reduced [6]. In wastewater treatment plants, human excrement is thought to be the major source of pharmaceuticals wastewater treatment plants (WWTPs) [7]. Anticancer medicines are only partially eliminated during sewage treatment methods due to their chemical features and they contaminate surface waters [8]. Recently, several studies have shown the occurrence of antitumoral drugs in the aquatic environment at $\mathrm{ng}-\mu \mathrm{g} \mathrm{\textrm {L } ^ { - 1 }}$ concentrations [9-11].

Numerous studies have shown increasing concentrations of platinum group elements in various parts of the water ecosystem, i.e., in drinking, ground and surface waters [12,13]. The major sources of platinum compounds in the environment are the emissions from catalytic converters of automobiles and effluents from hospitals. High levels of carcinogenic platinum compounds, such as oxaliplatin, ranging from 4.7 to 145 micrograms/liter, were observed in a study conducted on wastewater samples from hospital settings of cancer departments [11].

Pharmaceutical bioaccumulation has been documented in both laboratory [14-16] and field research [17,18]. Only Steinbach et al., 2013 [19] presented data on the bioaccumulation of a pharmaceutical (verapamil) in aquatic animals (Cyprinus carpio) during early life stages. In literature, a large amount of ecotoxicological data on anticancer drugs is present [20]. Unfortunately, there are few data on acute exposure to antitumoral drugs as environmental contaminants and their effects on the aquatic species, particularly the most vulnerable forms like larvae [21]. The Fish Embryo Toxicity (FET) test with D. rerio is a widely used protocol to assess the toxicity of environmental contaminants [22,23]. Other implications can be shown in the FET test, such as influences on developmental advancement, including as morphological deformities, delayed development, pericardial edema and yolk sac edema. In this study we evaluated the toxic effects of OXA on the development of the zebrafish embryos.

\section{Materials and Methods}

\subsection{Solutions Preparation}

OXA (Oxaliplatin SUN, $10 \mathrm{~mL}) 5 \mathrm{mg} / \mathrm{mL}$ was purchased from (SUN Pharmaceutical Industries Europe B.V. Polarisavenue 872132 JH Hoofddorp, Holland). The solution was diluted in embryo medium obtaining three concentrations ranging from 0.5 to 0.1 to $0.001 \mathrm{mg} / \mathrm{L}$ in 24 well plate (Labsolute, Th. Geyer GmbH \& Co. KG, Dornierstr. 4-6 D-71272 Renningen, Germany), one for each concentration and one plate with negative control (untreated).

\subsection{Zebrafish Maintenance and Breeding}

Wild type (WT) mature zebrafish with an age of 6 months were used for embryos production. Zebrafish were reared in the Centre for Experimental Fish Pathology (Centro di Ittiopatologia Sperimentale della Sicilia-CISS), Department of Veterinary Sciences, University of Messina, Italy. CISS has been accredited for the use and production of aquatic models for research since 2006 and all procedures were performed according to EU /63/2010 DL. The fish were fed both with dry and live food twice a day at 3\% of body weight (BW). For a successful reproduction, mature females and males were mated at 2:1 ratio. The day after, the eggs were collected, bleached and afterwards non-fertilized 
eggs were discarded. According to Directive 2010/63/EU and relating Italian DL 26/2014 on the protection of animals used for scientific purposes, experiments on zebrafish larvae up to five days $(120 \mathrm{~h}$ ) post fertilization and particularly ZFET are paired with alternative methods and thus they do not need ethical approval. The evaluation and authorization of projects involving the use of animals in experimental procedures refer to:

(a) Live non-human vertebrate animals, including: (i) independently feeding larval forms; and (ii) foetal forms of mammals as from the last third of their normal development;

(b) Live cephalopods.

\subsection{Zebrafish Embryo Toxicity (ZFET) Assay}

The toxicity of OXA solutions was established following the OECD guideline (OECD, Test No. 236: fish embryo acute toxicity (FET) test). Different concentrations of the OXA $(0.0010-0.5 \mathrm{mg} / \mathrm{L})$ were prepared using embryo medium and placed into 24 -well plate (1 embryo each well). Fertilized eggs ( $n=24$ in each plate for each replicate of an experimental group, 20 exposed to the drug and 4 used as negative controls) were transferred into 24-well plates with test solutions and incubated at $26^{\circ} \mathrm{C}$ at a $14: 10 \mathrm{~h}$ day/night light regime. The experiment was repeated three times. The entire mortality and developmental abnormalities of embryos and larvae were monitored and recorded at 24, 48, 72 and $96 \mathrm{~h}$ post fertilization (hpf) [24]. Coagulation, lack of somites, non-detachment of the tail and no heartbeat was considered as lethal endpoint. Furthermore, malformations of the embryos during development was evaluated as a teratogenic endpoint. In addition, the percentage of hatching and mortality were estimated. A stereo microscope was used to capture images and movies (Leica M205 C, Leica Microsystems Srl, Buccinasco Milano, Italy). Every 24 h, four separate endpoints were checked to see any malformations:

(a) embryo coagulation-can also occur within a few hours of the start of exposure and indicates a generic acute toxic effect;

(b) lack of somite formation-somite should be visible $12 \mathrm{~h}$ after fertilization; if absent, the embryo will not develop further, thus causing its death;

(c) non-detachment of the tail-detachment of the tail from the yolk can be observed 24 $\mathrm{h}$ after fertilization, indicating normal growth of the embryo;

(d) absence of heartbeat - the heartbeat is easily detectable $30 \mathrm{~h}$ after fertilization, its absence indicates the death of the embryo; embryo coagulation and absence of heartbeat were focused, as endpoints of mortality.

\subsection{Histopathological Analysis}

Larvae were collected and fixed in buffered $4 \%$ paraformaldehyde for $24 \mathrm{~h}$ at $4{ }^{\circ} \mathrm{C}$ for histological investigation. After that, they were dehydrated, rinsed and processed in an ascending order of alcohol (70-100\%), followed by xylene clearing. Paraffin wax was used to embed the samples, which were then placed on wooden blocks. Microtome was used to cut $5-\mu \mathrm{m}$ thick, thin sections. Haematoxylin and eosin were used to stain the slides (H\&E). Tissue ribbons were stretched by fixation on albumenized glass slides. Following that, the slides were inspected under a light microscope (Olympus-CX41, Olympus Italia S.r.l., Segrate, Italy).

\subsection{Total RNA Extraction and RT-PCR}

The total RNA from zebrafish larvae (10 per experimental group of each experiment) was homogenized and isolated in $0.50 \mathrm{~mL}$ TRIzol reagent (Invitrogen, Waltham, MA, USA) according to the manufacturer's instructions. Total RNA was isolated according to the manufacturer's instructions. The ratio of absorbance at $260-280 \mathrm{~nm}$, as well as the banding patterns on a $1 \%$ agarose formaldehyde gel, were used to verify the quality of the RNA in each sample. RNA quality was evaluated by gel electrophoresis, with the concentration measured with NanoDrop 2000 (Thermo Scientific, Waltham, MA, USA, iScript RT-PCR kit (Bio-Rad, Hercules, CA, USA)), which was used to synthesize first-strand cDNA according to manufacturer's recommendations. The reverse transcription master mix was 
prepared adding to $1 \mu \mathrm{g}$ of RNA template the iScript RT Su-permix ( $5 \times$ RT supermix with RNase H+ Moloney (gray cap, 25 or 100 reactions) murine leukemia virus (MMLV) reverse transcriptase, RNase inhibitor, dNTPs, oligo (dT), random primers, buffer, $\mathrm{MgCl}_{2}$ and stabilizers) and the nuclease-free water. The complete reaction mix was incubated in a thermal cycler (Priming $5 \mathrm{~min}$ at $25{ }^{\circ} \mathrm{C}$, Reverse transcription $20 \mathrm{~min}$ at $46{ }^{\circ} \mathrm{C}$, RT inactivation for one minute at $95^{\circ} \mathrm{C}$ ). Real-time PCR was performed with a $20-\mu \mathrm{L}$ volume containing $10-\mu \mathrm{L}$ of $1 \times$ SsoFast EvaGreen Supermix (Bio-Rad, Hercules, CA, USA), $1 \mu \mathrm{L}$ of cDNA, $7 \mu \mathrm{L}$ of RNase/DNase-free water and $500 \mathrm{nM}$ each primer. PCR conditions were initial denaturation at $95{ }^{\circ} \mathrm{C}$ for $15 \mathrm{~min}$, followed by 45 cycles of amplification at $95^{\circ} \mathrm{C}$ for $20 \mathrm{~s}$ and $60^{\circ} \mathrm{C}$ for $40 \mathrm{~s}$. Final extension at $60{ }^{\circ} \mathrm{C}$ for $60 \mathrm{~s}$ and hold at $4{ }^{\circ} \mathrm{C}$ were then performed on StepOnePlus Real-Time PCR System (Applied Biosystems, Foster City, CA, USA).The RT-PCR technique was adapted from a previous study [25]. Each gene in the present study was assessed in triplicate. The sequences of primers for the real-time PCR are shown in Table 1.

Table 1. Primers for real-time PCR.

\begin{tabular}{|c|c|c|}
\hline Gene & Primer Orientation & Nucleotide Sequence \\
\hline \multirow[t]{2}{*}{ b-actin } & forward & 5'-AGAGCTATGAGCTGCCTGACG-3' \\
\hline & reverse & 5'-CCGCAAGATTCCATACCCA-3' \\
\hline \multirow[t]{2}{*}{ casp-3 } & forward & 5'-CCGCTGCCCATCACTA-3' \\
\hline & reverse & 5'-ATCCTTTCACGACCATCT-3' \\
\hline \multirow[t]{2}{*}{ Bax } & forward & 5'-GGCTATTTCAACCAGGGTTCC-3' \\
\hline & reverse & 5'-TGCGAATCACCAATGCTGT-3' \\
\hline \multirow[t]{2}{*}{$b c l-2$} & forward & 5'-TCACTCGTTCAGACCCTCAT-3' \\
\hline & reverse & 5'-ACGCTTTCCACGCACAT-3' \\
\hline
\end{tabular}

\subsection{Cell Death and Image Analysis}

The cell death percentage was obtained by assessing the fluorescence using Zou et al.'s methodology [26]. Acridine orange, a nucleic acid-specific metachromatic dye that interacts with DNA and RNA via intercalation or electrostatic attraction stains necrotic or very late apoptotic cells; thus, acridine orange staining was used to detect cell death in live zebrafish embryos. Embryos were transferred into 24-well plates at $96 \mathrm{hpf}$ and treated with acridine orange for $30 \mathrm{~min}\left(7 \mu \mathrm{g} \mathrm{mL} \mathrm{L}^{-1}\right)$, in the dark at $28^{\circ} \mathrm{C}$. The zebrafish embryos were then rinsed in fresh embryo medium five times and anesthetized before visualization. The fluorescence intensity of each zebrafish larva was quantified with the Image J program (Version 1.8.0, National Institutes of Health, Bethesda, MD, USA).

\subsection{SOD and CAT Measurement}

The larvae from each plate were defrosted and homogenized on ice with $180 \mu \mathrm{L}$ icecold physiological saline. The supernatant was obtained by centrifuging the homogenate at $4000 \mathrm{~g}$ for $15 \mathrm{~min}$ at $4{ }^{\circ} \mathrm{C}$. As previously mentioned, the concentration of SOD and CAT in the supernatant was determined using commercial kits (Nanjing Jiancheng Bioengineering Institute, Nanjing, China) [27-31].

\subsection{Data Analysis}

Microsoft Excel was used to evaluate all of the raw spreadsheet data. GraphPad Prism 8.3.1 software (GraphPad, San Diego, CA, USA, 2020) was used to plot and statistically analyze graphs. To find significant differences between the mean values, a two-way anova analysis of variance was utilized (ANOVA-SNK). The data were tested for normal distribution with the Kolmogorov-Smirnov test $(p<0.05)$ and they were represented as mean \pm standard error of mean (SEM) (alpha value of 0.05 ). 


\section{Results}

\subsection{Mortality, Hatching Rate and Malformations}

Figure 1A depicts the development of OXA-exposed zebrafish embryos from 24 to $96 \mathrm{hpf}$. At $96 \mathrm{hpf}$, the $0.5 \mathrm{mg} / \mathrm{L}$ OXA-treated group had many morphogenetic defects, including spinal curvature, pericardial edema and tail deformity. Figure 1B depicts the embryos cumulative survival after exposure to OXA. In order of increasing concentration, survival rate was documented at 24, 48, 72 and 96 hpf. Calculations (GraphPad Prism 8.3.1 software, San Diego, CA, USA, 2020) have been used to determine the median lethal concentration (LC50) of OXA at $96 \mathrm{hpf}$, the LC50 was $0.5 \mathrm{mg} / \mathrm{L}$, resulting in a much higher mortality than the control group. At doses lower than $0.5 \mathrm{mg} / \mathrm{L}$, no particular decrease in survival rate was observed (does not exceed 25\% significantly); this shows that lower concentrations do not have a major impact on zebrafish larvae development. Because hatching is a critical time in zebrafish embryogenesis, the hatching rate is one of the most important indices for determining OXA developmental toxicity in zebrafish. According to the studies conducted, embryos started to hatch by $48 \mathrm{hpf}$ and finished by $72 \mathrm{hpf}$. Our results showed that $76 \%$ of the $0.001 \mathrm{mg} / \mathrm{L}$ group all embryos had hatched by $72 \mathrm{hpf}$, while in groups with concentrations of $0.1 \mathrm{mg} / 1$ and $0.5 \mathrm{mg} / 1$, the hatching rate was $75 \%$ and $61 \%$ respectively. Therefore, as shown in Figure $1 C$, the embryo-hatching rate was reduced in the OXA higher concentrations $(0.1-0.5 \mathrm{mg} / \mathrm{L})$, mostly in the highest dose treated group $(0.5 \mathrm{mg} / \mathrm{L})$. These data showed a slight dose-dependent decrease in the hatching rate in the 0.1 and $0.5 \mathrm{mg} / \mathrm{L}$ OXA-treated groups compared with the control group $(100 \%$ hatching at $72 \mathrm{hpf})$.

A CTRL

$0.001 \mathrm{mg} / \mathrm{L}$

$0.1 \mathrm{mg} / \mathrm{L}$ $0.5 \mathrm{mg} / \mathrm{L}$
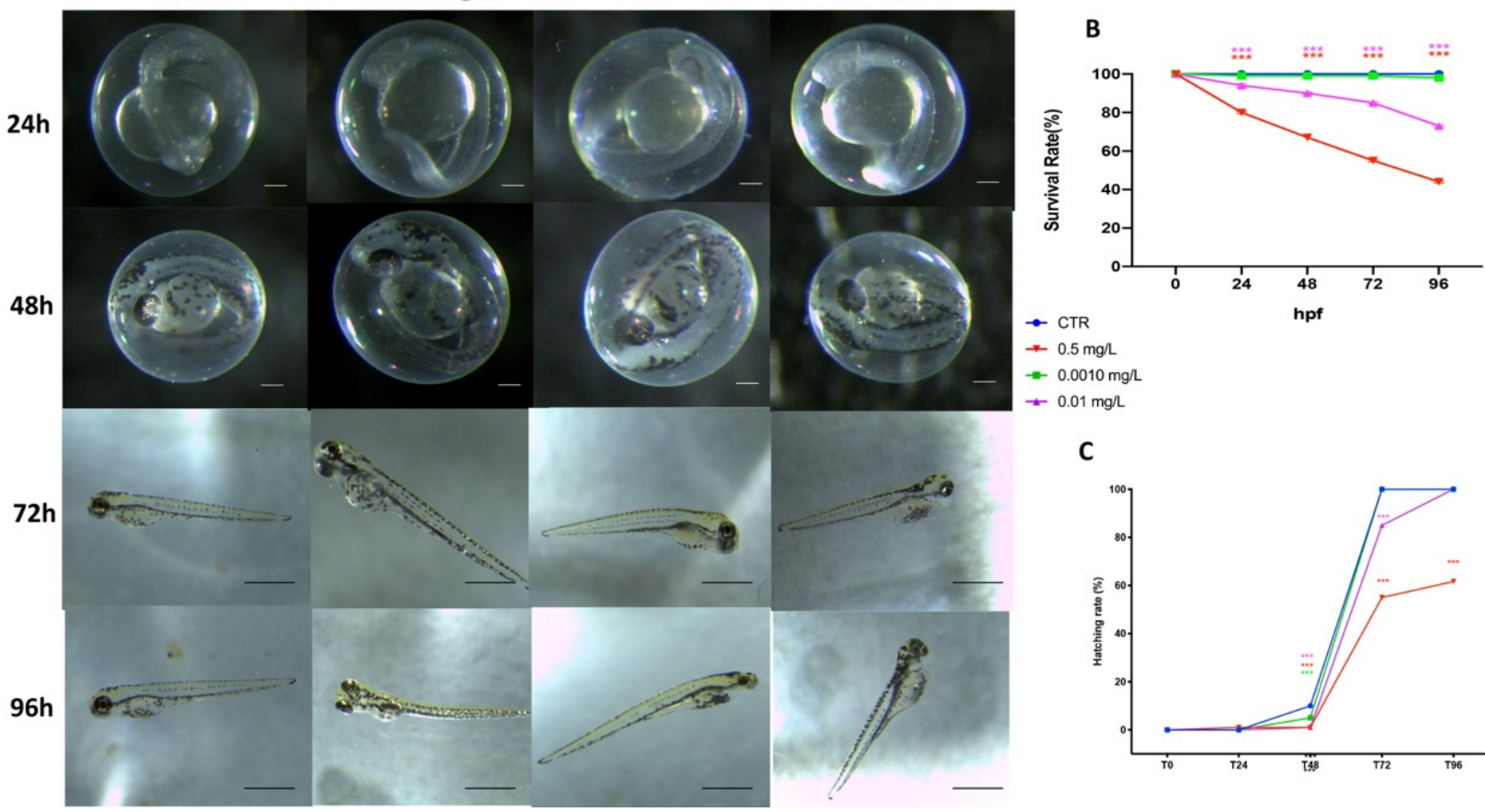

$+0.5 \mathrm{mg} / \mathrm{L}$

$\rightarrow 0.0010 \mathrm{mg} / \mathrm{l}$

$\neq 0.01 \mathrm{mgl}$

C

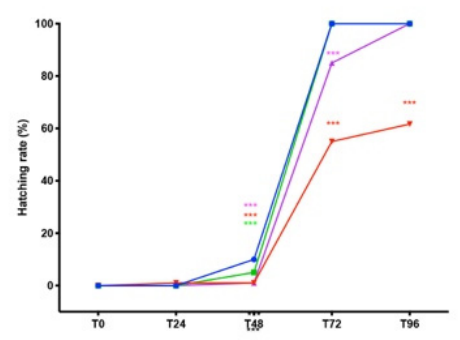

Figure 1. Embryo phenotypes, mortality and hatching rate after 24 to $96 \mathrm{~h}$ of exposure to OXA. (A) The embryo phenotypes in the unexposed and OXA-exposed groups. (B) The mortality rate in zebrafish embryos exposed to OXA. (C) The hatching rate in zebrafish embryos exposed to OXA. The asterisk denotes a statistically significant difference when compared with the CTRL: ${ }^{* * *} p<0.001$ versus control.

\subsection{OXA Effect on Stress Oxidative Pathway}

The results showed an increase of SOD and CAT expression levels related to oxidative damage after OXA exposure at high doses (0.1 and $0.5 \mathrm{mg} / \mathrm{L})$ (Figure 2). Contrarily, OXA 
at $0.001 \mathrm{mg} / \mathrm{L}$ did not show effect on stress oxidative in larval compared to CTRL group (Figure 2).
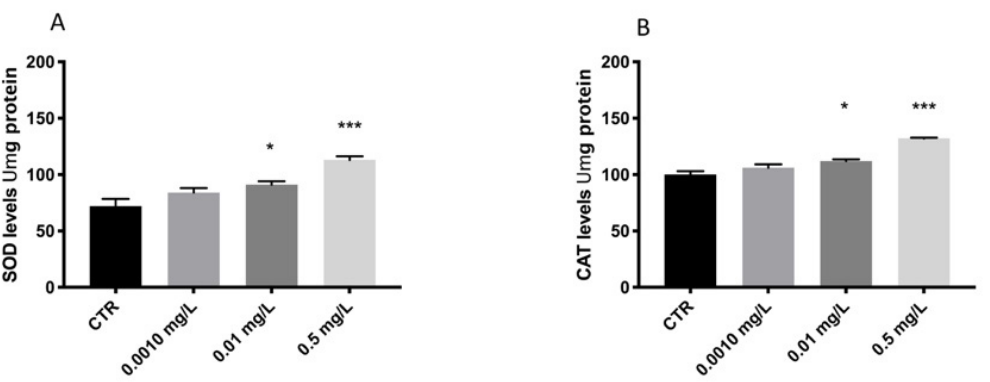

Figure 2. Effects of OXA exposure on activities of SOD (A) and CAT (B), in the larval zebrafish. Embryonic zebrafish was exposed to OXA for $96 \mathrm{hpf}$. Data are expressed as the mean $\pm \mathrm{SEM}$ of three replicates (about 10 larvae per replicate). The asterisk denotes a statistically significant difference when compared with the CTRL: ${ }^{*} p<0.05,{ }^{* * *} p<0.001$ versus control.

\subsection{Histological Analysis}

OXA produced noticeable effects in a dose dependent manner on the heart, liver, intestines and muscle, including mild fat liver degeneration with atrophy at $96 \mathrm{hpf}$, frayed gut villi with epithelial desquamation, as depicted in Figure 3. The OXA group at $0.001 \mathrm{mg} / \mathrm{L}$ showed no significant histological alteration compared to the CTRL group, while the 0.1 groups and even more the group with the higher dose $(0.5 \mathrm{mg} / \mathrm{L}$ of OXA) showed histological changes (more than $50 \%$ of the entire group) in intestine, infiltrate and edema in heart and muscle and also hepatocytes loss in liver.

CTRL

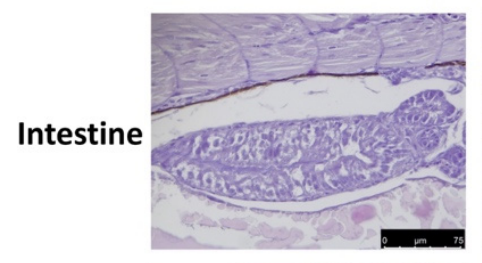

Muscle
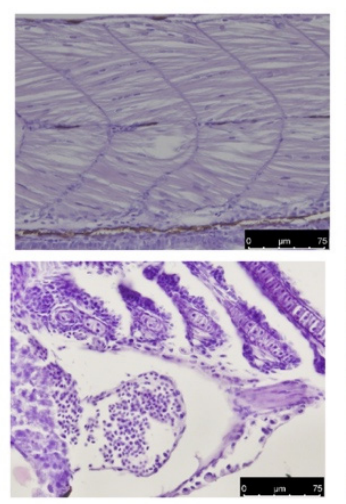

Heart

Liver

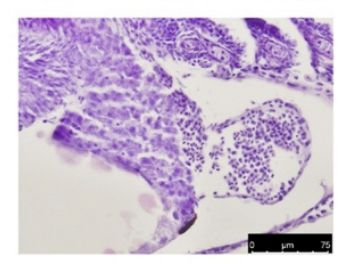

$0.001 \mathrm{mg} / \mathrm{L}$
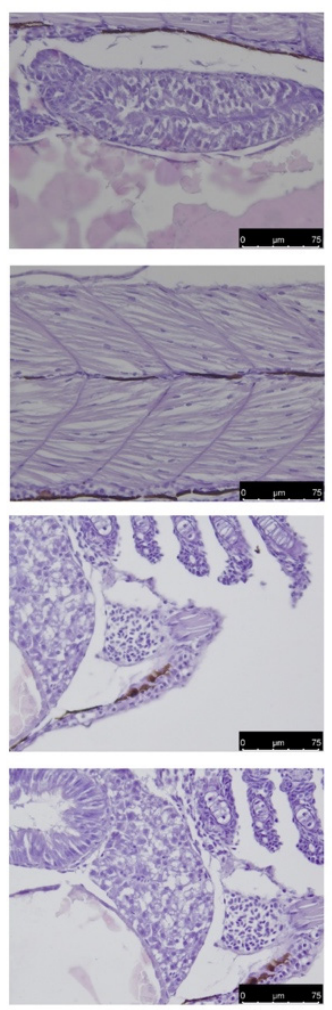

$0.1 \mathrm{mg} / \mathrm{L}$
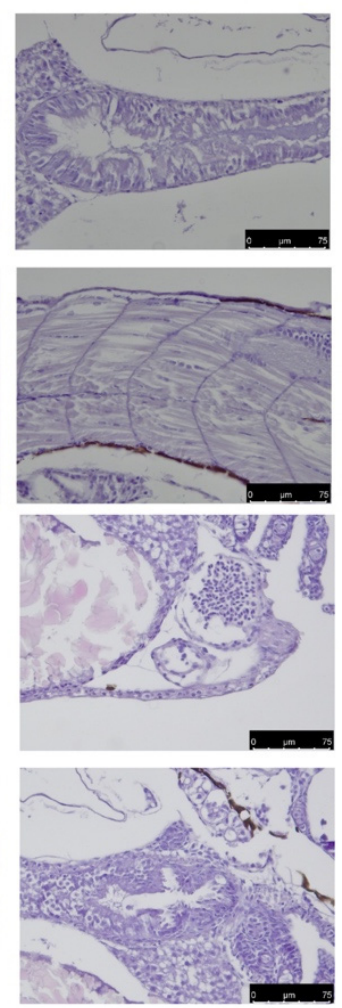

\section{$0.5 \mathrm{mg} / \mathrm{L}$}
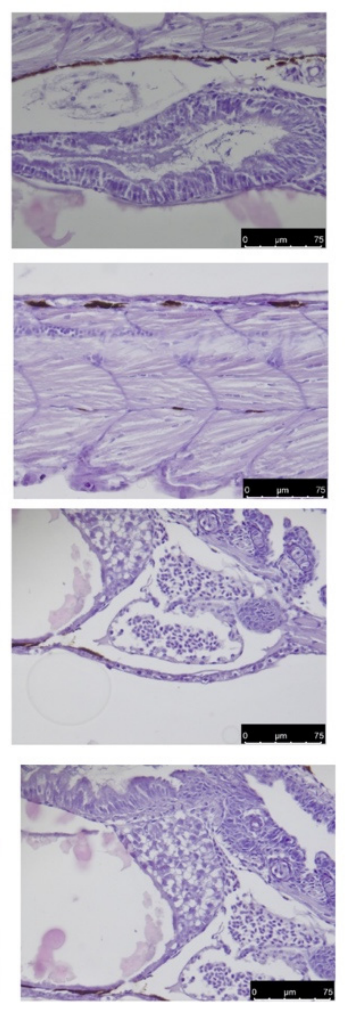

Figure 3. Histopathological changes in the hearts, livers, intestines and muscles of zebrafish larvae exposed to OXA at $96 \mathrm{hpf}$. Data are presented as means \pm SEM, or median with interquartile range for non-parametric data of 10 larvae for each group. Scale bars $40 \times$ magnification. 


\subsection{Cell Death Process}

Enhanced fluorescence intensities were clearly observed in OXA-exposed zebrafish larvae when compared to the CTRL. The cell death was forcefully increased in a dosedependent manner after OXA exposure. This value was reduced remarkably at $0.001 \mathrm{mg} / \mathrm{L}$ compared to the 0.1 and $0.5 \mathrm{mg} / \mathrm{L}$ group. The results indicate that OXA in a dose dependent manner induced cell death in zebrafish embryos. Moreover, we employed RT-PCR to assess the mRNA expression levels of larvae exposed to different OXA concentrations at $96 \mathrm{hpf}$ to determine the possible causes of the harmful effects generated by OXA. The expression levels of apoptosis-related genes (caspase- 3 and bax) rose with increasing OXA exposure dose, according to the RT-PCR data. With increasing OXA exposure levels, bcl-2 mRNA expression was downregulated(Figure 4).

A

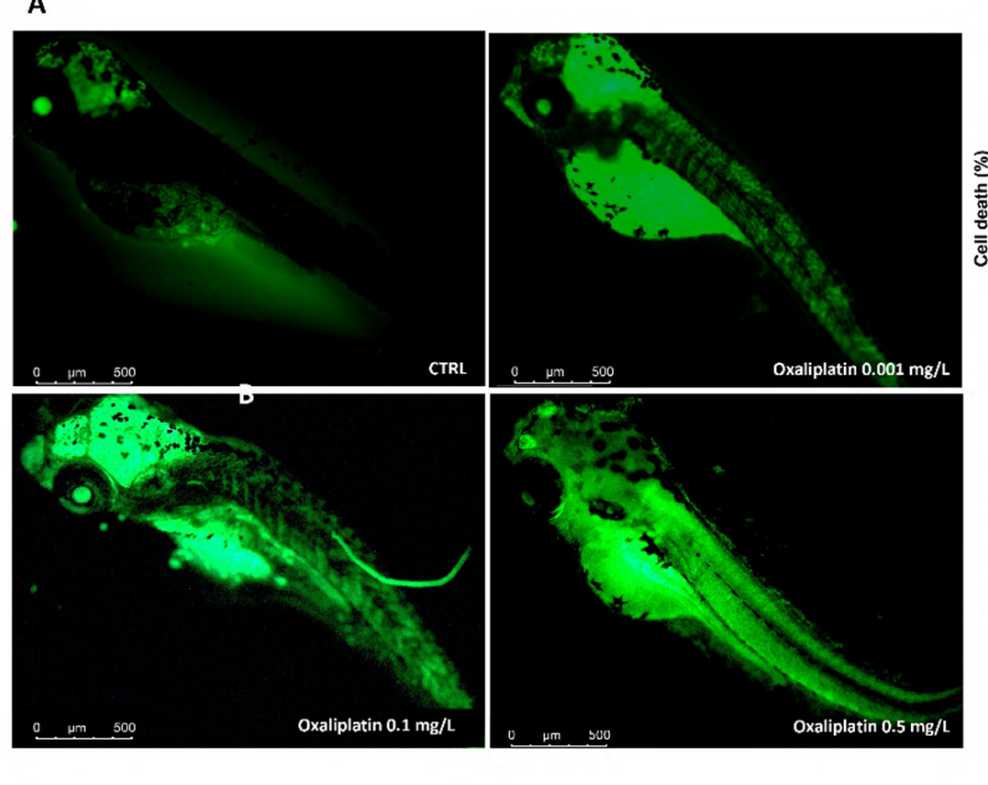

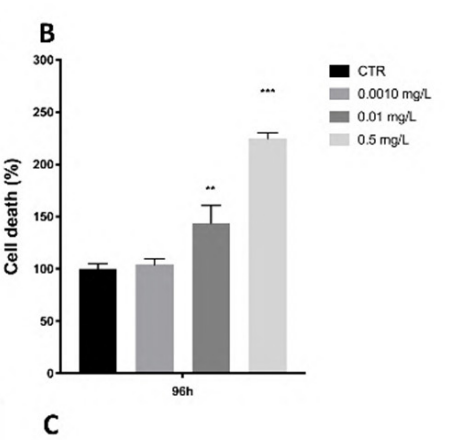

C

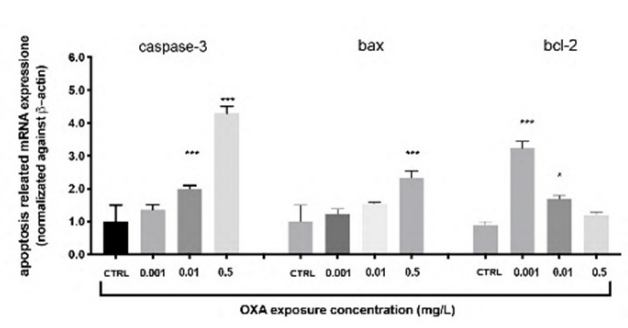

Figure 4. The OXA exposure effects on cell death zebrafish embryos. At 96 hpf, OXA 0.001, 0.1, $0.5 \mathrm{mg} / \mathrm{L}$ exposure, the levels of cell death were observed and photographed by a fluorescence microscope after staining with acridine orange (A). Percentage of cell death histogram (B). The results are expressed as mean of three independent experiment data. Related gene expression levels of apoptotic pathway in zebrafish embryos exposed to OXA at concentrations of $0.001,0.1,0.5 \mathrm{mg} / \mathrm{L}$ at $48 \mathrm{hpf}(\mathrm{C})$. The fold change from the CTRL group is used to reflect the mRNA expression levels. ${ }^{*} p<0.05,{ }^{* *} p<0.01,{ }^{* * *} p<0.001$ versus control. Scale bars $4 \times$ magnification.

\section{Discussion}

Several studies have already highlighted the presence of different typologies of drugs in aquatic environments [32]. The development of environmental quality standards and/or guidelines for pharmaceuticals in seawater, sediments and biota would be aided by the expansion of data on the ecological consequences of pharmaceuticals present in the examined environment. The proposed short-term approaches to minimize the exposure of humans, animals and ecosystems to these substances include extensive monitoring of pharmaceuticals in the environment and their influence on living species [33-35]. In this manuscript we investigated the effects of OXA exposure at three different concentrations. At $0.001 \mathrm{mg} / \mathrm{L}$, OXA treatments did not show any noticeable signs of toxicity, whereas doses of 0.1 and $0.5 \mathrm{mg} / \mathrm{L}$ significantly affected hatching rate and zebrafish embryo development. It has been widely demonstrated that OXA therapy caused embryonic teratogenesis, which included pericardial edema and spinal malformation. The most prevalent type of malformation, spinal cord teratogenesis, may be linked to an ion imbalance (such as calcium and phosphorus) or a decrease in myosin, which are both required for 
development $[36,37]$. As already demonstrated in other studies, OXA is able to interfere and block protein synthesis in a dose-dependent manner [5]. For this reason, it is very plausible to consider this mechanism of action also involved in the defections found in the development of the larvae and at the same time in their hatching rate. Because hatching is such an important stage in zebrafish embryogenesis, the lower hatching rate was attributed to structural and functional disruptions that took place during the embryonic stage [38,39]. In addition, the difficulty of emerging larvae to break the eggshell [40] or the inhibition of mitosis or embryogenesis [41] also played a role in the developmental delay. Our research highlighted a slight dose-dependent drop-in hatching rate. Moreover, this delay in hatching is also a good indicator of developmental toxicity. According to the study performed, OXA exposition at moderate doses caused embryonic teratogenesis, which included pericardial edema, spinal curvature, uninflated swim bladders and twisted tails. Histological analysis of zebrafish larvae confirmed the detrimental effects of OXA exposure showing heart, liver, intestine and muscle injury. Several studies reported that drug-induced oxidative stress has two basic mechanisms: an increase in ROS generation and a loss in cellular antioxidant defenses [42,43]. The main cause of oxidative stress is reactive oxygen species (ROS). Excessive production of ROS in vivo causes oxidative stress [44], since oxygen free radicals can react excessively with SOD and CAT, causing an imbalance in the body's antioxidant protection mechanism. SOD is an antioxidant enzyme that can protect the body from oxidative damage caused by the environment, eliminate ROS and prevent lipid peroxidation [31]. The ability of antioxidant defenses was diminished in the high-exposure group, which could be because negative feedback regulation is important in low concentration stimulation. These findings showed that oxidative stress was triggered in OXA-exposed zebrafish embryos and had a key role in OXA developmental toxicity. Several studies have largely highlighted the involvement of oxidative stress in the activation of apoptosis processes $[45,46]$. These correlations between oxidative damage and cell death have also been demonstrated in several studies conducted in both larvae and adult zebrafish [47,48]. Moreover, involvement of OXA in triggering of apoptosis mechanisms has already been documented in literature [49-51]. In the present study, we demonstrated how exposure to a dose of $0.5 \mathrm{mg} / \mathrm{L}$ of OXA not only causes an imbalance in antioxidant defenses but also results in an increase in markers related to the apoptotic process. In fact, exposure to OXA increased both the levels of apoptosis-related genes (caspase- 3 and bax) and a downregulation of the mRNA expression of anti-apoptotic gene bcl-2. This increase in apoptotic markers is also accompanied by an increase in the percentage of cell death seen in OXA-exposed larvae.

\section{Conclusions}

Finally, OXA induced a dose-dependent increase in developmental harm in zebrafish embryos, as demonstrated by an increase in mortality and deformities and a delay in hatching. The information gathered in this study will aid in deciphering the mechanisms of OXA-induced developmental harm.

Author Contributions: Conceptualization, S.C.; methodology D.I., R.C., R.F. and D.D.P.; validation, M.C., R.S., E.G., T.G. and N.S.; formal analysis and investigation, A.F.P. and F.C.; resources, R.F.; data curation J.M.A., R.D., R.F. and D.D.P.; writing—original draft preparation, D.I., R.C. and A.F.P.; writing-review and editing, M.C., R.S. and A.F.P.; visualization J.M.A., F.C. and D.D.P.; supervision, E.G. and T.G.; project administration, S.C. and N.S. All authors have read and agreed to the published version of the manuscript.

Funding: This research received no external funding.

Institutional Review Board Statement: Not applicable.

Informed Consent Statement: Not applicable.

Data Availability Statement: Not applicable.

Conflicts of Interest: There is no conflict of interest. 


\section{References}

1. Poklar, N.a.; Pilch, D.S.; Lippard, S.J.; Redding, E.A.; Dunham, S.U.; Breslauer, K.J. Influence of cisplatin intrastrand crosslinking on the conformation, thermal stability, and energetics of a 20-mer DNA duplex. Proc. Natl. Acad. Sci. USA 1996, 93, 7606-7611. [CrossRef]

2. Rudd, G.; Hartley, J.; Souhami, R. Persistence of cisplatin-induced DNA interstrand crosslinking in peripheral blood mononuclear cells from elderly and young individuals. Cancer Chemother. Pharmacol. 1995, 35, 323-326. [CrossRef] [PubMed]

3. Osterauer, R.; Fassbender, C.; Braunbeck, T.; Kohler, H.R. Genotoxicity of platinum in embryos of zebrafish (Danio rerio) and ramshorn snail (Marisa cornuarietis). Sci. Total Environ. 2011, 409, 2114-2119. [CrossRef] [PubMed]

4. Karas, B.F.; Hotz, J.M.; Buckley, B.T.; Cooper, K.R. Cisplatin alkylating activity in zebrafish causes resistance to chorionic degradation and inhibition of osteogenesis. Aquat. Toxicol. 2020, 229, 105656. [CrossRef] [PubMed]

5. Raymond, E.; Faivre, S.; Woynarowski, J.M.; Chaney, S.G. Oxaliplatin: Mechanism of action and antineoplastic activity. Semin. Oncol. 1998, 25, 4-12.

6. Jerremalm, E. Biotransformation of the Antineoplastic Drug Oxaliplatin: Importance for Effects and Side Effects. Institutionen för onkologi-patologi/Department of Oncology-Pathology; Caroline Institute: Stockholm, Sweden, 4 April 2008.

7. Mezzelani, M.; Gorbi, S.; Regoli, F. Pharmaceuticals in the aquatic environments: Evidence of emerged threat and future challenges for marine organisms. Mar. Environ. Res. 2018, 140, 41-60. [CrossRef]

8. Aguirre-Martinez, G.V.; DelValls, T.A.; Martin-Diaz, M.L. General stress, detoxification pathways, neurotoxicity and genotoxicity evaluated in Ruditapes philippinarum exposed to human pharmaceuticals. Ecotoxicol. Environ. Saf. 2016, 124, 18-31. [CrossRef]

9. Aherne, G.W.; Hardcastle, A.; Nield, A.H. Cytotoxic drugs and the aquatic environment: Estimation of bleomycin in river and water samples. J. Pharm. Pharmacol. 1990, 42, 741-742. [CrossRef]

10. Lenz, K.; Koellensperger, G.; Hann, S.; Weissenbacher, N.; Mahnik, S.N.; Fuerhacker, M. Fate of cancerostatic platinum compounds in biological wastewater treatment of hospital effluents. Chemosphere 2007, 69, 1765-1774. [CrossRef]

11. Lenz, K.; Hann, S.; Koellensperger, G.; Stefanka, Z.; Stingeder, G.; Weissenbacher, N.; Mahnik, S.N.; Fuerhacker, M. Presence of cancerostatic platinum compounds in hospital wastewater and possible elimination by adsorption to activated sludge. Sci. Total Environ. 2005, 345, 141-152. [CrossRef]

12. Wildner, H. Kalibration, Probenzufuhr und Detektion fur diePlatinbestimmung im sub pg/g-Bereich. In Proceedings of the 3 Platin-Anwendertreffen, Munich, Germermy, 14-15 October 1996; Lustig, S., Schramel, P., Eds.; PGSP-Forschungszentrum, Institute fur Ecologische Chemie: Munich, Germermy.

13. Alt, F.; Eschnauer, H.; Mergler, B.; Messerschmidt, J.; Tölg, G. A contribution to the ecology and enology of platinum. Fresenius' J. Anal. Chem. 1997, 357, 1013-1019. [CrossRef]

14. Chen, Y.; Zhou, J.; Cheng, L.; Zheng, Y.; Xu, J. Sediment and salinity effects on the bioaccumulation of sulfamethoxazole in zebrafish (Danio rerio). Chemosphere 2017, 180, 467-475. [CrossRef] [PubMed]

15. Grabicova, K.; Lindberg, R.H.; Östman, M.; Grabic, R.; Randak, T.; Larsson, D.J.; Fick, J. Tissue-specific bioconcentration of antidepressants in fish exposed to effluent from a municipal sewage treatment plant. Sci. Total Environ. 2014, 488, 46-50. [CrossRef]

16. Nakamura, Y.; Yamamoto, H.; Sekizawa, J.; Kondo, T.; Hirai, N.; Tatarazako, N. The effects of pH on fluoxetine in Japanese medaka (Oryzias latipes): Acute toxicity in fish larvae and bioaccumulation in juvenile fish. Chemosphere 2008, 70, 865-873. [CrossRef] [PubMed]

17. Grabicova, K.; Grabic, R.; Fedorova, G.; Fick, J.; Cerveny, D.; Kolarova, J.; Turek, J.; Zlabek, V.; Randak, T. Bioaccumulation of psychoactive pharmaceuticals in fish in an effluent dominated stream. Water Res. 2017, 124, 654-662. [CrossRef] [PubMed]

18. Ramirez, A.J.; Brain, R.A.; Usenko, S.; Mottaleb, M.A.; O’Donnell, J.G.; Stahl, L.L.; Wathen, J.B.; Snyder, B.D.; Pitt, J.L.; PerezHurtado, P. Occurrence of pharmaceuticals and personal care products in fish: Results of a national pilot study in the United States. Environ. Toxicol. Chem. 2009, 28, 2587-2597. [CrossRef]

19. Steinbach, C.; Fedorova, G.; Prokes, M.; Grabicova, K.; Machova, J.; Grabic, R.; Valentova, O.; Kroupova, H.K. Toxic effects, bioconcentration and depuration of verapamil in the early life stages of common carp (Cyprinus carpio L.). Sci. Total Environ. 2013, 461, 198-206. [CrossRef]

20. Li, D.; Chen, H.; Liu, H.; Schlenk, D.; Mu, J.; Lacorte, S.; Ying, G.-G.; Xie, L. Anticancer drugs in the aquatic ecosystem: Environmental occurrence, ecotoxicological effect and risk assessment. Environ. Int. 2021, 153, 106543. [CrossRef]

21. Isidori, M.; Lavorgna, M.; Russo, C.; Kundi, M.; Žegura, B.; Novak, M.; Filipič, M.; Mišík, M.; Knasmueller, S.; de Alda, M.L. Chemical and toxicological characterisation of anticancer drugs in hospital and municipal wastewaters from Slovenia and Spain. Environ. Pollut. 2016, 219, 275-287. [CrossRef]

22. Zhang, C.; Willett, C.; Fremgen, T. Zebrafish: An animal model for toxicological studies. Curr. Protoc. Toxicol. 2003, 17, 1-7. [CrossRef]

23. McGrath, P.; Li, C.-Q. Zebrafish: A predictive model for assessing drug-induced toxicity. Drug Discov. Today 2008, 13, 394-401. [CrossRef] [PubMed]

24. Parenti, C.C.; Ghilardi, A.; Della Torre, C.; Magni, S.; Del Giacco, L.; Binelli, A. Evaluation of the infiltration of polystyrene nanobeads in zebrafish embryo tissues after short-term exposure and the related biochemical and behavioural effects. Environ. Pollut. 2019, 254, 112947. [CrossRef] [PubMed] 
25. Zhang, Y.; Liu, K.; Hassan, H.M.; Guo, H.; Ding, P.; Han, L.; He, Q.; Chen, W.; Hsiao, C.-D.; Zhang, L. Liver fatty acid binding protein deficiency provokes oxidative stress, inflammation, and apoptosis-mediated hepatotoxicity induced by pyrazinamide in zebrafish larvae. Antimicrob. Agents Chemother. 2016, 60, 7347-7356. [CrossRef]

26. Zou, Y.; Fu, X.; Liu, N.; Duan, D.; Wang, X.; Xu, J.; Gao, X. The synergistic anti-inflammatory activities of agaro-oligosaccharides with different degrees of polymerization. J. Appl. Phycol. 2019, 31, 2547-2558. [CrossRef]

27. Liu, Y.; Wang, J.; Wei, Y.; Zhang, H.; Xu, M.; Dai, J. Induction of time-dependent oxidative stress and related transcriptional effects of perfluorododecanoic acid in zebrafish liver. Aquat. Toxicol. 2008, 89, 242-250. [CrossRef] [PubMed]

28. Jin, Y.; Zhang, X.; Shu, L.; Chen, L.; Sun, L.; Qian, H.; Liu, W.; Fu, Z. Oxidative stress response and gene expression with atrazine exposure in adult female zebrafish (Danio rerio). Chemosphere 2010, 78, 846-852. [CrossRef]

29. Jin, Y.; Wang, L.; Ruan, M.; Liu, J.; Yang, Y.; Zhou, C.; Xu, B.; Fu, Z. Cypermethrin exposure during puberty induces oxidative stress and endocrine disruption in male mice. Chemosphere 2011, 84, 124-130. [CrossRef]

30. Stucki, G.E.; Alexander, M.A. Role of dissolution rate and solubility in biodegradation of aromatic compounds. Appl. Environ. Microbiol. 1987, 53, 2603. [CrossRef]

31. Jin, Y.; Liu, Z.; Liu, F.; Ye, Y.; Peng, T.; Fu, Z. Embryonic exposure to cadmium (II) and chromium (VI) induce behavioral alterations, oxidative stress and immunotoxicity in zebrafish (Danio rerio). Neurotoxicol. Teratol. 2015, 48, 9-17. [CrossRef]

32. Nastrucci, C.; Cesario, A.; Russo, P. Anticancer drug discovery from the marine environment. Recent Pat. Anticancer Drug Discov. 2012, 7, 218-232. [CrossRef]

33. Hylland, K.; Robinson, C.D.; Burgeot, T.; Martínez-Gómez, C.; Lang, T.; Svavarsson, J.; Thain, J.E.; Vethaak, A.D.; Gubbins, M.J. Integrated chemical and biological assessment of contaminant impacts in selected European coastal and offshore marine areas. Mar. Environ. Res. 2017, 124, 130-138. [CrossRef] [PubMed]

34. Vethaak, A.D.; Davies, I.M.; Thain, J.E.; Gubbins, M.J.; Martínez-Gómez, C.; Robinson, C.D.; Moffat, C.F.; Burgeot, T.; Maes, T.; Wosniok, W. Integrated indicator framework and methodology for monitoring and assessment of hazardous substances and their effects in the marine environment. Mar. Environ. Res. 2017, 124, 11-20. [CrossRef] [PubMed]

35. Klatte, S.; Schaefer, H.-C.; Hempel, M. Pharmaceuticals in the environment-A short review on options to minimize the exposure of humans, animals and ecosystems. Sustain. Chem. Pharm. 2017, 5, 61-66. [CrossRef]

36. Oliveira, R.; Domingues, I.; Grisolia, C.K.; Soares, A.M. Effects of triclosan on zebrafish early-life stages and adults. Environ. Sci. Pollut. Res. 2009, 16, 679-688. [CrossRef]

37. Jiao, L.; Li, D.-D.; Yang, C.-L.; Peng, R.-Q.; Guo, Y.-Q.; Zhang, X.-S.; Zhu, X.-F. Reactive oxygen species mediate oxaliplatin-induced epithelial-mesenchymal transition and invasive potential in colon cancer. Tumor Biol. 2016, 37, 8413-8423. [CrossRef]

38. Samaee, S.-M.; Rabbani, S.; Jovanović, B.; Mohajeri-Tehrani, M.R.; Haghpanah, V. Efficacy of the hatching event in assessing the embryo toxicity of the nano-sized TiO2 particles in zebrafish: A comparison between two different classes of hatching-derived variables. Ecotoxicol. Environ. Saf. 2015, 116, 121-128. [CrossRef] [PubMed]

39. Liu, J.; Zhu, Y.; Luo, G.-Z.; Wang, X.; Yue, Y.; Wang, X.; Zong, X.; Chen, K.; Yin, H.; Fu, Y. Abundant DNA 6mA methylation during early embryogenesis of zebrafish and pig. Nat. Commun. 2016, 7, 1-7. [CrossRef] [PubMed]

40. Papiya, S.; Kanamadi, R. Effect of mercurial fungicide Emisan ${ }^{\circledR}-6$ on the embryonic developmental stages of zebrafish, Brachydanio (Danio rerio). J. Adv. Zool. 2000, 21, 12-18.

41. Ismail, A.; Yusof, S. Effect of mercury and cadmium on early life stages of Java medaka (Oryzias javanicus): A potential tropical test fish. Mar. Pollut. Bull. 2011, 63, 347-349. [CrossRef]

42. Baillie, T.A.; Rettie, A.E. Role of biotransformation in drug-induced toxicity: Influence of intra-and inter-species differences in drug metabolism. Drug Metab. Pharmacokinet. 2011, 26, 15-29. [CrossRef]

43. Leung, L.; Kalgutkar, A.S.; Obach, R.S. Metabolic activation in drug-induced liver injury. Drug Metab. Rev. 2012, 44, 18-33. [CrossRef] [PubMed]

44. Wijesinghe, W.; Jeon, Y.J.; Ramasamy, P.; Wahid, M.E.A.; Vairappan, C.S. Anticancer activity and mediation of apoptosis in human HL-60 leukaemia cells by edible sea cucumber (Holothuria edulis) extract. Food Chem. 2013, 139, 326-331. [CrossRef] [PubMed]

45. Franco, R.; Sánchez-Olea, R.; Reyes-Reyes, E.M.; Panayiotidis, M.I. Environmental toxicity, oxidative stress and apoptosis: Menage a trois. Mutat. Res. Genet. Toxicol. Environ. Mutagenesis 2009, 674, 3-22. [CrossRef] [PubMed]

46. Ozben, T. Oxidative stress and apoptosis: Impact on cancer therapy. J. Pharm. Sci. 2007, 96, 2181-2196. [CrossRef]

47. Choi, J.E.; Kim, S.; Ahn, J.H.; Youn, P.; Kang, J.S.; Park, K.; Yi, J.; Ryu, D.-Y. Induction of oxidative stress and apoptosis by silver nanoparticles in the liver of adult zebrafish. Aquat. Toxicol. 2010, 100, 151-159. [CrossRef]

48. Xia, Q.; Wei, L.; Zhang, Y.; Kong, H.; Shi, Y.; Wang, X.; Chen, X.; Han, L.; Liu, K. Psoralen induces developmental toxicity in zebrafish embryos/larvae through oxidative stress, apoptosis, and energy metabolism disorder. Front. Pharmacol. 2018, 9, 1457. [CrossRef]

49. Faivre, S.; Chan, D.; Salinas, R.; Woynarowska, B.; Woynarowski, J.M. DNA strand breaks and apoptosis induced by oxaliplatin in cancer cells. Biochem. Pharmacol. 2003, 66, 225-237. [CrossRef]

50. Arango, D.; Wilson, A.; Shi, Q.; Corner, G.; Aranes, M.; Nicholas, C.; Lesser, M.; Mariadason, J.; Augenlicht, L. Molecular mechanisms of action and prediction of response to oxaliplatin in colorectal cancer cells. Br. J. Cancer 2004, 91, 1931-1946. [CrossRef]

51. William-Faltaos, S.; Rouillard, D.; Lechat, P.; Bastian, G. Cell cycle arrest and apoptosis induced by oxaliplatin (L-OHP) on four human cancer cell lines. Anticancer Res. 2006, 26, 2093-2099. 